\title{
Taurocyamine-utilizing Mutant of Pseudomonas aeruginosa with Altered Induction of 3-Guanidinopropionate Amidinohydrolase
}

\author{
Takamitsu YorIfuJI, Katsuhiko SAwAdA and Chikashi ToKudA \\ Department of Agricultural and Biological Chemistry, Shinshu University, \\ Minamiminowa Kamiina, Nagano 399-45, Japan
}

Received June 13, 1986

\begin{abstract}
A mutant, strain M-6, capable of utilizing taurocyamine (2-guanidinoethanesulfonate) as a nitrogen source was isolated from the parent strain, Pseudomonas aeruginosa GB-4, a derivative of wild-type $P$. aeruginosa PAO1 lacking the ability to produce guanidinobutyrase (EC 3.5.3.7). 3Guanidinopropionate amidinohydrolase (EC class 3.5.3), which acts slowly on taurocyamine, was induced effectively by only 3-guanidinopropionate in the parent strain, while the enzyme of strain M-6 was induced by taurocyanime, guanidinoacetate, 3-guanidinopropionate, 4-guanidinobutyrate, and guanidinosuccinate. Strain M-6 synthesized a slight amount of the enzyme constitutively. The enzyme partially purified from strain M-6 exhibited substrate specificity similar to that of the wild-type strain. The mutant could grow also on 4-guanidinobutyrate, unlike the parent strain. These results indicate that strain M- 6 acquired the ability to grow on taurocyamine by virtue of a mutation at the regulatory gene for 3-guanidinopropionate amidinohydrolase, which led to alteration of the specificity of the regulatory protein.
\end{abstract}

A number of mutants of microorganisms that have acquired new metabolic capabilities

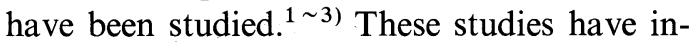
dicated that the most common way for bacteria to acquire a new metabolic function is to synthesize constitutively an enzyme, which already has an activity toward the new growth substrate but is not induced by the substrate in the parent strain. For example, mutants of Aerobacter (Klebsiella) aerogenes that synthesized L-fucose isomerase constitutively could grow on D-arabinose; this isomerase was not induced by $\mathrm{D}$-arabinose in the parent strain. ${ }^{4)}$

Pseudomonas aeruginosa $\mathrm{PAO} 1$ produces 3-guanidinopropionate amidinohydrolase (GPH, EC class 3.5.3) and guanidinobutyrase (GBH, EC 3.5.3.7). ${ }^{5}$ GPH has been highly purified and characterized in our laboratory; $;$,7) this enzyme is not induced by taurocyamine (2-guanidinoethanesulfonate), but catalyzes hydrolysis of its guanidino group to form urea at a rate of $11 \%$ of that toward 3guanidinopropionate. Our previous paper reported a taurocyamine-utilizing mutant of
Pseudomonas sp. ATCC 14676; it was strongly suggested that the mutant produced GBH of altered substrate specificity to act on taurocyamine. ${ }^{8}$ This paper deals with a taurocyamine-utilizing mutant from $P$. aeruginosa strain GB-4, a derivative of the wild-type strain PAO1 lacking the ability to synthesize GBH. In mutant strain M-6, there was little constitutive synthesis of GPH, and the enzyme was induced by some guanidino compounds including taurocyamine. This indicates that the mutant had a mutation at the regulatory gene of GPH, but it was not a typical constitutive mutant.

\section{MATERIALS AND METHODS}

Chemicals. Taurocyamine, 3-guanidinopropionate, 4guanidinobutyrate, 5-guanidinovalerate, guanidinosuccinate, and 2-guanidinoethyl sulfate were synthesized from taurine, $\beta$-alanine, 4 -aminobutyrate, 5 -aminovalerate, $\mathrm{L}$ aspartate, and 2-aminoethyl sulfate, respectively, by amidination with $S$-methylisothiourea sulfate under the conditions described by Kimmel ${ }^{9)}$ and recrystallized from water. Amino acids and other chemicals were purchased 
from Nakarai Chemicals, Ltd., unless specified otherwise.

Organism. Pseudomonas aeruginosa strain GB-4, which was used as the parent strain, was a kind gift of Dr. H. Matsumoto of the School of Medicine, Shinshu University. This strain, which required L-methionine for growth and lacked the ability to produce $\mathrm{GBH}$, is a derivative of wild-type $P$. aeruginosa PAO1 (ATCC 15692). Strain GB-4 grew well on 3-guanidinopropionate as a nitrogen source, but could not grow on 4guanidinobutyrate.

Media and culture conditions. Asparagine-succinate medium, which contained $0.1 \%$ asparagine and $0.5 \%$ sodium succinate, and taurocyamine-succinate medium, which contained $0.05 \%$ taurocyamine and $0.5 \%$ sodium succinate, were prepared by adding $0.01 \%$ L-methionine into the asparagine-succinate medium $\mathrm{II}^{8)}$ and the taurocyamine-succinate medium, ${ }^{8)}$ respectively, described in the previous paper; peptone medium was prepared as described. ${ }^{8)}$ Guanidinopropionate and guanidinobutyrate media were prepared by replacing taurocyamine in taurocyamine-succinate medium with 3-guanidinopropionate and 4-guanidinobutyrate, respectively. Solid media for plate cultures were prepared by adding $1.5 \%(\mathrm{w} / \mathrm{v})$ of agar (AGAR PURIFIED, Difco Laboratories, Detroit, Mich.) into liquid media. For the isolation of mutants, cells were cultivated in a $20-\mathrm{ml} \mathrm{L}$-shaped test tube or in a $500-\mathrm{ml}$ culture flask with a side arm $15 \mathrm{~mm}$ in diameter (Wheaton Scientific, Millville, N. J.) at $28^{\circ} \mathrm{C}$ with aeration. Growth was monitored at $570 \mathrm{~nm}$ with a Hitachi EPO-B colorimeter.

Isolation of taurocyamine-utilizing mutants. All the cells of strain GB-4 grown in $15 \mathrm{ml}(2 \times 7.5 \mathrm{ml})$ of the asparagine-succinate medium for $8 \mathrm{hr}$ were suspended in $16 \mathrm{ml}$ of $0.85 \% \mathrm{NaCl}$ to give $2.1 \times 10^{8}$ cells $/ \mathrm{ml}$, and the suspension was uv-irradiated for $10 \mathrm{sec}$ under the conditions described previously $;^{8)} 0.3 \%$ of the irradiated cells survived. To the cell suspension was added $5 \mathrm{ml}$ of the sterile asparagine-succinate medium that was supplemented with additional L-asparagine to give a final concentration of $0.4 \%$. The culture was grown in a culture flask at $28^{\circ} \mathrm{C}$ for $12 \mathrm{hr}$ in the dark, and then $200 \mathrm{ml}$ of the sterile taurocyamine-succinate medium was added into the culture. This diluted culture was incubated for $103 \mathrm{hr}$ at $28^{\circ} \mathrm{C}$ with aeration. The cells grown were subcultured three times by transferring $0.2 \mathrm{ml}$ of the culture into $200 \mathrm{ml}$ of the fresh taurocyamine-succinate medium and incubating the new culture until the turbidity at $570 \mathrm{~nm}$ increased to about 0.3 . The subcultured cells in $0.1-\mathrm{ml}$ aliquots of the broth were plated on taurocyamine-succinate agar plates after appropriate dilution with $0.85 \% \mathrm{NaCl}$. After incubation of the plates at $41^{\circ} \mathrm{C}$ for 2 days, the colonies obtained were stocked on the taurocyamine-succinate agar slants.
Assay of enzymes and analytical methods. GPH was assayed by the method described in the previous paper, ${ }^{6}$ ) by measuring urea formed from 3-guanidinopropionate. The rate of hydrolysis of taurocyamine or 4-guanidinobutyrate with GPH was measured similarly. Guanidino compounds were assayed colorimetrically by the method of Rosenberg et al. ${ }^{10)}$ Urea was assayed with diacetyl monoxime and antipyrine by the method of Prescott and Jones. ${ }^{11)}$ Protein in the cell extracts. was assayed by the method of Bradford ${ }^{12)}$ with Bio-Rad protein assay dye reagent (Bio-Rad Laboratories, Richmond, Calif.) using bovine serum albumin as the standard. Protein in purified enzyme fractions was assayed from the absorbance at $280 \mathrm{~nm}$ using an $E(1 \%)$ value of 10.0 .

Induction of $G P H$ with guanidino compounds. The cells of strain M-6 or strain GB-4 were grown in a 2,000-ml shaking flask containing $350 \mathrm{ml}$ of the asparaginesuccinate medium at $30^{\circ} \mathrm{C}$ for $7 \mathrm{hr}$. Each of the $50-\mathrm{ml}$ aliquots was placed in a $500-\mathrm{ml}$ shaking flask and $50 \mathrm{ml}$ of $20 \mathrm{~mm}$ potassium phosphate buffer, $\mathrm{pH} 7.5$, containing $0.2 \mathrm{mM} \mathrm{MnCl}_{2}$ and $0.2 \%$ guanidino compound was added. The cell suspension was incubated at $30^{\circ} \mathrm{C}$ for $5 \mathrm{hr}$ with aeration. The cells were harvested by centrifugation, washed once with $0.85 \% \mathrm{NaCl}$, and suspended in $1.0 \mathrm{ml}$ of $20 \mathrm{~mm}$ Tris- $\mathrm{HCl}$ buffer, $\mathrm{pH} 8.0$, containing $1.0 \mathrm{~mm}$ 2-mercaptoethanol and $0.1 \mathrm{mM} \mathrm{MnCl}_{2}$. The cell extract was prepared by disrupting the cells with a Kaijo Denki $19 \mathrm{kHz}$ sonic disintegrator for $20 \mathrm{sec}$ at $10^{\circ} \mathrm{C}$ or below, followed by centrifugation at $15,000 \times g$ for $10 \mathrm{~min}$ to remove cell debris. The enzyme activity was assayed as described above by use of 3-guanidinopropionate, taurocyamine, and 4-guanidinobutyrate as the substrates.

Purification of $G P H$ from strain $M-6$. The cells of strain M-6 were grown in 15 liters of the taurocyamine-succinate medium under conditions described previously. ${ }^{6)}$ The methods for preparation of the cell extract, ammonium sulfate fractionation, and DEAE-cellulose column chromatography were similar to those described in the previous paper. $\left.{ }^{6}\right)$ The cell extract contained $1,050 \mathrm{mg}$ of protein and 2,320 units of GPH. The DEAE-cellulose fraction contained $47 \mathrm{mg}$ of protein and 1,220 units of GPH. The enzyme was dialyzed against $20 \mathrm{~mm}$ Tris- $\mathrm{HCl}$ buffer, $\mathrm{pH} 8.0$, containing $1.0 \mathrm{~mm}$ 2-mercaptoethanol and $0.1 \mathrm{mM} \mathrm{MnCl}_{2}$ (buffer TM), and put on a column of DEAE-Toyopearl (Toyo Soda Mfg. Co., Ltd., $1.2 \times 45$ $\mathrm{cm}$ ) equilibrated with buffer TM containing $0.2 \mathrm{M} \mathrm{KCl}$. After the column was washed with $150 \mathrm{ml}$ of the equilibration buffer, the enzyme was eluted with a linear $\mathrm{KCl}$ gradient of $125 \mathrm{ml}$ each of buffer TM containing $0.2 \mathrm{M}$ $\mathrm{KCl}$ and buffer containing $0.6 \mathrm{M} \mathrm{KCl}$. The active fractions contained $4.0 \mathrm{mg}$ of protein and 840 units of GPH. 


\section{RESULTS}

Growth of strain GB-4 on guanidino compounds

When the cells of $P$. aeruginosa strain GB-4, which was used as the parent strain in this study, were grown in the taurocyaminesuccinate medium, they grew initially with a doubling time of $130 \mathrm{~min}$ for a short time; this burst of growth was also observed in the absence of a nitrogen source. Thereafter, the cells grew very slowly with a doubling time of $85 \mathrm{hr}$. In the guanidinopropionate medium, the cells grew rapidly with a doubling time of $88 \mathrm{~min}$. This strain failed to grow on 4-guanidinobutyrate, unlike wild-type $P$. aeruginosa PAO1.

\section{Isolation of taurocyamine-utilizing mutant}

The apparent growth was observed after cultivation of the uv-irradiated cells of strain GB-4 for $103 \mathrm{hr}$ in the taurocyamine-succinate medium. The cells grown were subcultured three times in the medium, and then thirty colonies were isolated and stocked as candidates of taurocyamine-utilizing mutant. After testing of these strains for L-methionine requirement and growth rate on taurocyamine, strain M-6 was selected for the further experiments. Strain M-6 required L-methionine for growth, grew well on taurocyamine, and produced GPH when grown in the guanidinopropionate medium. The minimum doubling time of the cells of strain M-6. grown in the taurocyamine-succinate medium was $130 \mathrm{~min}$ (Fig. 1). Taurocyamine was almost consumed during the cultivation. These results indicate that strain M-6 aquired the ability to grow rapidly on taurocyamine with a doubling time comparable to that observed with the parent strain growing on 3-guanidinopropionate.

\section{Time study of GPH induction in strain M-6}

The cells of the parent strain and strain M-6 were grown in the asparagine-succinate medium for $8 \mathrm{hr}$ at $30^{\circ} \mathrm{C}$, and then an equal volume of $20 \mathrm{~mm}$ potassium phosphate buffer, pH 7.5 , containing $0.2 \%$ taurocyamine and $0.2 \mathrm{mM} \mathrm{MnCl}_{2}$ was added, and the incubation

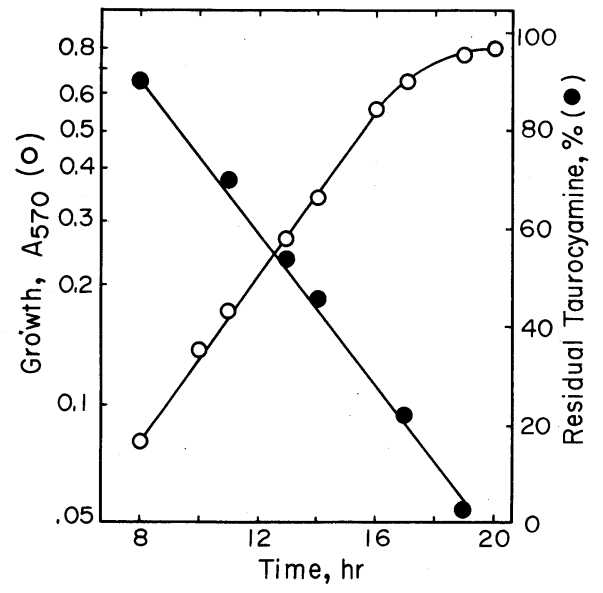

FIG. 1. Growth of Strain M-6 in TaurocyamineSuccinate Medium.

The cells of strain M-6 were cultivated at $30^{\circ} \mathrm{C}$ in $8.0 \mathrm{ml}$ of the taurocyamine-succinate medium, which was inoculated by transferring $0.1 \mathrm{ml}$ of a $8.0-\mathrm{ml}$ culture in the asparagine-succinate medium. Each sample, $0.1 \mathrm{ml}$, was withdrawn at the time indicated and the concentration of taurocyamine was measured. (O), turbidity at $570 \mathrm{~nm}$; (O), taurocyamine concentration.

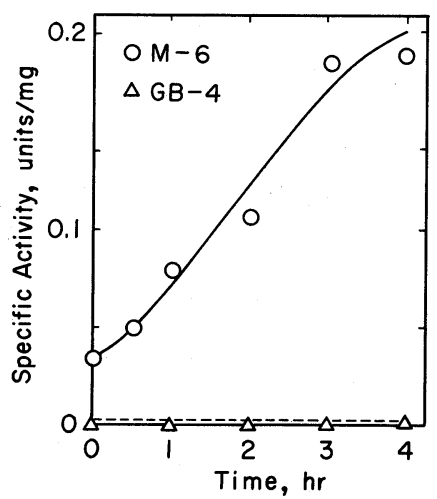

FIG. 2. Induction of GPH in Strains M-6 and GB-4 with Taurocyamine.

The cells of strain M- 6 or strain GB- 4 were cultivated in a $2,000-\mathrm{ml}$ shaking flask containing $200 \mathrm{ml}$ of the asparagine-succinate medium at $30^{\circ} \mathrm{C}$ for $8 \mathrm{hr}$. To the culture was added $200 \mathrm{ml}$ of $20 \mathrm{~mm}$ potassium phosphate buffer, $\mathrm{pH} 7.5$, containing $0.2 \%$ taurocyamine and $0.2 \mathrm{~mm}$ $\mathrm{MnCl}_{2}$, and incubation was continued with aeration. At the time indicated, a sample $(50 \mathrm{ml})$ was withdrawn, the cells were corrected and washed, and the extract was prepared as described under Materials. AND METHODS. GPH activities of the extracts of the cells of strain M-6 (O) and those of the cells of strain GB-4 $(\triangle)$ were assayed. The activity toward taurocyamine was assayed but is not shown. 
was continued with aeration. The samples were withdrawn at various times, the cell extracts were prepared, and the activities of the extracts to hydrolyze 3-guanidinopropionate and taurocyamine were assayed (Fig. 2). Unlike the parent strain, the extract of the cells of strain M-6 grown on asparagine showed a low GPH activity, and the GPH specific activity of the extract increased with an increase in the time of incubation with taurocyamine. Taurocyamine was hydrolyzed with relative rates of around $12 \%$ of those toward 3-guanidinopropionate with all the extracts of M-6 cells incubated with taurocyamine. These results indicate that taurocyamine induced GPH in the cells of strain M- 6 but not in the cells of the parent strain, and that the cells of strain M-6 synthesized a slight amount of the enzyme constitutively.

Induction of $\mathrm{GPH}$ in strain $M-6$ by various guanidino compounds

The cells of strain M-6 and the parent strain grown on L-asparagine were incubated in $10 \mathrm{~mm}$ potassium phosphate buffer, $\mathrm{pH} 7.5$, containing $0.1 \mathrm{~mm} \mathrm{MnCl}_{2}$ and $0.1 \%$ guanidino compound. The enzyme activity of the extract of the cells was assayed with 3-guanidinopropionate, taurocyamine, or 4-guanidinobutyrate (Table I). GPH of the parent strain was induced strongly. by 3-guanidinopropionate and very weakly by guanidinoacetate. By contrast, GPH of strain M-6 was induced considerably by guanidinoacetate, taurocyamine, 4-guanidinobutyrate, guanidinosuccinate, and an unknown compound in peptone, as well as 3-guanidinopropionate. A slight constitutive synthesis of GPH in strain M-6 was also shown in this experiment. These results indicate that the mutation in strain M-6 led to a broadened inducer spectrum for GPH and to a slight constitutive synthesis of the enzyme.

\section{Substrate specificity of GPH from strain $M-6$}

GPH of strain M-6 was partially purified 94-

Table I. Induction of GPH in Strains M-6 AND GB-4

\begin{tabular}{|c|c|c|c|c|}
\hline \multirow{2}{*}{ Inducer } & \multirow{2}{*}{ Strain } & \multicolumn{3}{|c|}{$\begin{array}{c}\text { Activity } \\
(\mu \mathrm{mol} / \mathrm{min} / \mathrm{mg})^{a}\end{array}$} \\
\hline & & GP & $\mathrm{TC}$ & GB \\
\hline \multirow[t]{2}{*}{ Guanidinoacetate } & M-6 & 1.3 & 0.27 & 0.10 \\
\hline & GB-4 & 0.02 & trace & trace \\
\hline \multirow[t]{2}{*}{ 3-Guanidinopropionate } & M-6 & 3.3 & 0.68 & 0.24 \\
\hline & GB-4 & 4.4 & 0.65 & 0.25 \\
\hline \multirow[t]{2}{*}{ Taurocyamine } & M-6 & 0.15 & 0.016 & 0.005 \\
\hline & GB-4 & 0.006 & 0 & 0 \\
\hline \multirow[t]{2}{*}{ 4-Guanidinobutýrate } & M-6 & 0.16 & 0.016 & 0.006 \\
\hline & GB-4 & trace & 0 & 0 \\
\hline \multirow[t]{2}{*}{ 5-Guanidinovalerate } & M-6 & 0.005 & 0 & 0 \\
\hline & GB-4 & 0 & 0 & 0 \\
\hline \multirow[t]{2}{*}{ Guanidinosuccinate } & M-6 & 0.11 & trace & 0 \\
\hline & GB-4 & 0 & 0 & 0 \\
\hline \multirow[t]{2}{*}{ 2-Guanidinoethyl sulfate } & M-6 & 0.006 & 0 & 0 \\
\hline & GB-4 & 0 & 0 & 0 \\
\hline \multirow[t]{2}{*}{ Creatine } & M-6 & trace & 0 & 0 \\
\hline & GB-4 & 0 & 0 & 0 \\
\hline \multirow[t]{2}{*}{ Peptone } & M-6 & 0.047 & trace & 0 \\
\hline & GB-4 & 0 & 0 & 0 \\
\hline \multirow[t]{2}{*}{ None } & M-6 & 0.011 & 0 & 0 \\
\hline & GB-4 & 0 & 0 & 0 \\
\hline
\end{tabular}

a The value indicated is the activity toward 3-guanidinopropionate (GP), taurocyamine (TC), or 4guanidinobutyrate (GB).

Table II. Purification of GPH from Strain M-6

\begin{tabular}{|c|c|c|c|c|c|}
\hline & \multirow{2}{*}{ Step } & \multirow{2}{*}{$\begin{array}{l}\text { Protein } \\
(\mathrm{mg})\end{array}$} & \multicolumn{3}{|c|}{$\begin{array}{l}\text { Activity }(\mu \mathrm{mol} / \mathrm{min} / \mathrm{mg})^{a} \\
\text { (Relative activity, } \%)\end{array}$} \\
\hline & & & GP & $\mathrm{TC}$ & GB \\
\hline 1. & Sonic extract & 1,050 & $2.2(100)$ & $0.29(13)$ & $0.11(5)$ \\
\hline 2. & Ammonium sulfate & 511 & $7.0(100)$ & $1.0 \quad(14)$ & $0.20(3)$ \\
\hline 3. & DEAE-cellulose & 47 & $26 \quad(100)$ & $3.8 \quad(15)$ & $1.2(5)$ \\
\hline 4. & DEAE-Toyopearl & 4 & $210 \quad(100)$ & $35 \quad(17)$ & $12 \quad(6)$ \\
\hline
\end{tabular}

a The value indicated is the activity toward 3-guanidinopropionate (GP), taurocyamine (TC), or 4-guanidinobutyrate (GB). 


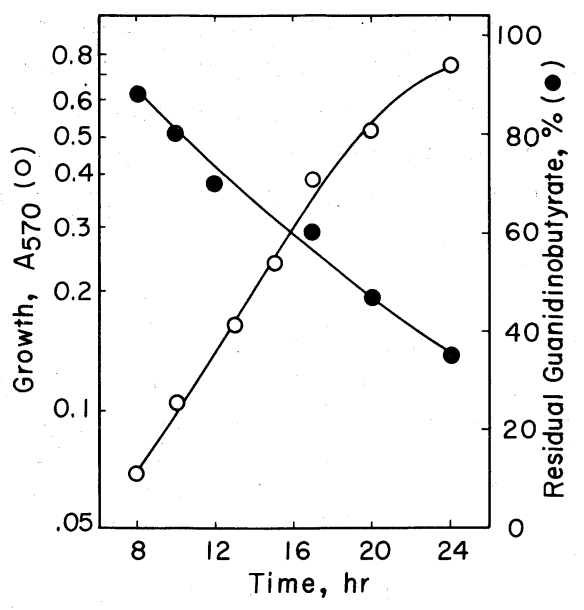

FIG. 3. Growth of Strain M-6 Cells in Guanidinobutyrate Medium.

The experimental conditions were the same as those described in Fig. 1 except that the guanidinobutyrate medium was used. The growth of cells $(O)$ and the concentration of 4-guanidinobutyrate $(\boldsymbol{O})$ were measured similarly.

fold by a four-step procedure similar to that described in our earlier paper. ${ }^{6)}$ Table II summarizes the purification. The activities of the individual fractions toward taurocyamine and 4-guanidinobutyrate, compared with those toward 3-guanidinopropionate, were close; about $15 \%$ for taurocyamine and about $5 \%$ for 4-guanidinobutyrate. The values obtained in our earlier experiment for highly purified GPH of the wild-type strain were $11 \%$ for taurocyamine and $3 \%$ for 4 -guanidinobutyrate. ${ }^{6}$ ) These observations indicate that the substrate specificities of GPH produced by strain M-6 and the enzyme of the wild-type strain were closely similar.

\section{Growth of strain M-6 on 4-guanidinobutyrate}

Strain GB-4, the parent strain, which lacked the ability to produce GBH, could not grow on 4-guanidinobutyrate as the nitrogen source. The data in Table II show that 4-guanidinobutyrate, a poor substrate of GPH, became an inducer of GPH in strain M-6. Thus, it was expected that strain M-6 could grow on 4-guanidinobutyrate. The strain grew well in the guanidinobutyrate medium with a mini- mum doubling time of about $200 \mathrm{~min}$, and $60 \%$ of 4 -guanidinobutyrate was consumed during cultivation for $24 \mathrm{hr}$ (Fig. 3).

\section{DISCUSSION}

The parent strain GB- 4 produces GPH, but does not produce $\mathrm{GBH}$, which wild-type Pseudomonas aeruginosa PAO1 does produce. GPH of the wild-type strain hydrolyzes also taurocyamine and 4-guanidinobutyrate with relative rates of $11 \%$ and $3 \%$, respectively, as fast as 3-guanidinopropionate. ${ }^{6)}$ The growth of strain GB-4 on taurocyamine is very slow, probably due to the low level of GPH induced with taurocyamine; the doubling time is $85 \mathrm{hr}$. This strain cannot grow on 4-guanidinobutyrate. Strain M-6 derived from strain GB-4 grows rapidly on taurocyamine with a doubling time of $130 \mathrm{~min}$, about forty times as fast as the parent strain. Thus, we think it is reasonable to refer to the strain as a taurocyamine-utilizing mutant. In strain M-6, a low level of GPH is synthesized constitutively, and taurocyamine, which is substantially not an inducer of GPH in the parent strain, elicits further synthesis of the enzyme. In addition, guanidinoacetate, 4-guanidinobutyrate, and guanidinosuccinate are the inducers of GPH in the mutant. These results indicate that the mutant produces an altered regulatory protein of lowered specificity for inducer, and this seems to enable the mutant to grow on taurocyamine, and also on 4-guanidinobutyrate. The transport system may be unchanged. 4-Guanidinobutyrate induces $\mathrm{GBH}$ and serves as a nitrogen source in wild-type strain PAO1. This implies that the compound permeates into the cell of the parent strain. It fails to induce the GPH of the parent strain, while it induces the enzyme of strain M-6. GPH may be unchanged; the substrate specificity of GPH purified from strain M-6 is close to that of the enzyme of the wild-type strain.

Although strain M-6 seems to bear a mutation at the regulatory gene for GPH, the regulation of GPH synthesis is almost con- 
served in the strain; the constitutive GPH level in non-induced cells is very low. Mutants of similar type have been found in D-arabinoseutilizing mutants of Klebsiella aerogenes. ${ }^{13)}$ Many mutants of bacteria which acquired new catabolic activity gained the activity by virtue of a mutation at the regulatory gene for an existing enzyme that led to constitutive enzyme synthesis. ${ }^{1 ~}{ }^{\sim 3}$ An inevitable view, as discussed by $\mathrm{Hall},{ }^{3)}$ is that consitutive enzyme synthesis may be wasteful and hence disadvantageous in the natural environment where the new resource is absent. The taurocyamine-utilizing mutant M-6, as well as the D-arabinoseutilizing mutants mentioned above, may not have such a disadvantage, since the ability to repress GPH synthesis is almost conserved.

The mutation in strain M-6 has allowed guanidinoacetate and guanidinosuccinate to induce GPH. These compounds are not the substrates of the enzyme, and hence they are gratuitous (non-substrate) inducers of the enzyme in this strain. Taurocyamine-utilizing mutants were obtained directly from wild-type Pseudomonas sp. ATCC 14676, in which taurocyamine was a gratuitous inducer of $\mathrm{GBH}{ }^{8}{ }^{8}$ One of the mutants appeared to produce altered GBH capable of hydrolyzing taurocyamine. The mutation at the regulatory gene of strain M-6 has, therefore, given rise to a possibility that a point mutation at the structural gene for GPH allows, in some cases, the enzyme to act on guanidinoacetate or guanidinosuccinate and it permits the organism to grow on the compound. Although our attempts to isolate such mutants have been unsuccessful, these types of mutation, which cause alternate changes of inducer and substrate specificity of an enzyme and thereby provide new catalytic and regulatory functions, might possible to occur in nature, presumably accompanied with neutral and advantageous mutations.

Acknowledgments. We thank Dr. Hideki Matsumoto of the School of Medicine, Shinshu University for the kind gift of bacterial mutants. We also thank Mr. Yoshimi Inoue for his experimental assistance. This work was supported in part by a Grant-in-Aid for Scientific Research (No. 60560109) from Ministry of Education, Science and Culture of Japan.

\section{REFERENCES}

1) P. H. Clarke, "The Bacteria," Vol. 6, ed. by L. N. Ornston and J. R. Sokatch, Academic Press Inc., New York, 1978, p. 137.

2) R. P. Mortlock, Annu. Rev. Microbiol., 36, 259 (1982).

3) B. G. Hall, "Evolution of Genes and Proteins," ed. by M. Nei and R. K. Koehn, Sinauer Associates Inc., Sunderland, Mass., 1983, p. 234.

4) E. J. Oliver and R. P. Mortlock, J. Bacteriol. 108, 287 (1971).

5) T. Yorifuji and I. Sugai, Agric. Biol. Chem., 42, 1789 (1978).

6) T. Yorifuji, I. Sugai, H. Matsumoto and A. Tabuchi, Agric. Biol. Chem., 46, 1361 (1982).

7) T. Yorifuji, T. Kobayashi, A. Tabuchi, Y. Shiritani and K. Yonaha, Agric. Biol. Chem., 47, 2825 (1983).

8) T. Yorifuji, Y. Shiritani, S. Eguchi and K. Yonaha, J. Appl. Biochem., 5, 375 (1983).

9) J. R. Kimmel, Methods Enzymol., 11, 584 (1967).

10) H. Rosenberg, A. H. Ennor and J. F. Morrison, Biochem. J., 63, 153 (1956).

11) L. M. Prescott and M. E. Jones, Anal. Biochem., 32, 408 (1969).

12) M. M. Bradford, Anal. Biochem., 72, 248 (1976).

13) E. J. St. Martin and R. P. Mortlock, J. Bacteriol., 127, 91 (1976). 